\title{
BMJ Open Progression of disease preceding lower extremity amputation in Denmark: a longitudinal registry study of diagnoses, use of medication and healthcare services 14 years prior to amputation
}

\author{
Pia Søe Jensen, ${ }^{1,2}$ Janne Petersen, ${ }^{1,3}$ Klaus Kirketerp-Møller, ${ }^{4}$ Ingrid Poulsen, ${ }^{5}$ \\ Ove Andersen ${ }^{1}$
}

To cite: Jensen PS, Petersen J, Kirketerp-Møller K, et al. Progression of disease preceding lower extremity amputation in Denmark: a longitudinal registry study of diagnoses, use of medication and healthcare services 14 years prior to amputation. BMJ Open 2017;7:e016030. doi:10.1136/ bmjopen-2017-016030

- Prepublication history and additional material for this paper are available online. To view these files, please visit the journal online (http://dx.doi org/10.1136/bmjopen-2017016030).

Received 25 January 2017 Revised 9 June 2017 Accepted 4 July 2017

CrossMark

For numbered affiliations see end of article.

Correspondence to

Pia Søe Jensen;

Ann.Pia.Soee.Lytken.Jensen@ regionh.dk

\section{ABSTRACT}

Objectives Patients with non-traumatic lower extremity amputation are characterised by high age, multi-morbidity and polypharmacy and long-term complications of atherosclerosis and diabetes. To ensure early identification of patients at risk of amputation, we need to gain knowledge about the progression of diseases related to lower extremity amputations during the years preceding the amputation.

Design A retrospective population-based national registry study.

Setting The study includes data on demographics, diagnoses, surgery, medications and healthcare services from five national registries. Data were retrieved from 14 years before until 1 year after the amputation. Descriptive statistics were used to describe the progression of diseases and use of medication and healthcare services.

Participants An unselected cohort of patients ( $\geq 50$ years; $\mathrm{n}=2883$ ) subjected to a primary non-traumatic lower extremity amputation in 2010 or 2011 in Denmark. Results The prevalence of atherosclerosis, hypertension and diabetes was $70 \%, 53 \%$ and $49 \%$, respectively. Among patients with atherosclerosis, $42 \%$ had not received cholesterol-lowering treatment even though $87 \%$ had visited their general practitioner within the last year prior to amputation. Further, 16\% were diagnosed with diabetes at the time of the amputation. The prevalence of cardiovascular diseases increased from $22 \%$ to $70 \%$, atherosclerosis from $5 \%$ to $53 \%$ and diabetes from $17 \%$ to $35 \%$ over the 14 years preceding major amputation. Of all patients, $64 \%$ had been in contact with the hospital or outpatient clinics within the last 3 years, and $29 \%$ received a prescription of opioids 3 years prior to the amputation.

Conclusion Among patients with non-traumatic lower extremity amputation, one-third live with undiagnosed and untreated atherosclerosis and one-sixth suffer from undiagnosed diabetes despite continuous contacts to general practitioner and the hospital. This study emphasises a need for enhanced focus, among both hospital clinicians and general practitioners, on the early identification of atherosclerosis and diabetes.

\section{Strengths and limitations of the study}

- The strengths of this national registry study were the inclusion of data describing diagnoses and use of medication and healthcare services during the last 14 years preceding non-traumatic lower extremity amputation performed in Denmark.

- The use of national registry which enables the inclusion of all patients who had undergone a lower limb amputation in Denmark and thereby limits the risk of selection bias.

- The main limitation was the lack of a control group. An age-matched, sex-matched and geographically matched control group would have allowed differentiation between disease progression due to ageing and disease progression leading to amputation. An inherent limitation was that the data did not allow an estimation of patient compliance with the prescribed medication.

\section{INTRODUCTION}

Lower extremity amputation (LEA) is a severe event associated with loss of mobility, pain, decreased quality of life, major disfigurement and increased risk of reamputation and hospitalisation. ${ }^{1-3}$ Even though the worldwide incidence of LEA has declined over the last 2 decades, significant variations persist: from 5.8 to 31 per $10^{5}$ individuals in different populations. ${ }^{4}$ The reported 1-year mortality rate was $12 \%-58 \%,{ }^{5-8}$ with the highest mortality rate $(45 \%-58 \%)$ associated with above-the-knee amputations (AKAs). ${ }^{9} 10$ Age and the severity of comorbidities are the most prominent prognostic factors for mortality after LEA. $^{67}$

The most prevalent comorbidities in patients with LEA are atherosclerosis primary as periphery vascular disease (PAD) and diabetes. ${ }^{4}$ 11-13 Studies have reported the 
prevalence of diabetes to be between $52 \%$ and $64 \%,{ }^{35} 14$ and approximately $80 \%$ of the patients with LEA are either diagnosed with diabetes or PAD. ${ }^{12}$ In a cohort of patients with diabetes, $18 \%$ had a cardiovascular disease (CVD) with PAD being most prevalent. ${ }^{15}$ Among patients diagnosed with both diabetes and PAD, the risk of amputation is 1.5 times higher than in patients diagnosed with PAD alone and five times higher than in patients only diagnosed with diabetes. ${ }^{13}$ The global prevalence of diabetes and PAD among patients with LEA varies among populations due to ethnicity and socioeconomic. ${ }^{416}$ Currently, the global prevalence of diabetes is estimated to be $9 \%$ of which $90 \%$ is characterised as type 2 diabetes ${ }^{17}$ and is expected to continue to increase over the next 20 years to $10 \%$. During the last decade, the global prevalence of PAD has increased by $23 \%$, with the highest increase among low-income countries. ${ }^{18}$ The risk factors for PAD are age, smoking, diabetes, hypertension, dyslipidaemia and obesity. ${ }^{19}$ The National Institute For Health and Clinical Excellence guidelines for lower limb peripheral arterial disease state that there is substantial evidence establishing benefits for lowering cholesterol drugs for patients with $\mathrm{PAD}$, and the use of limb-saving procedure is also recommended. ${ }^{20}$ The benefits of cholesterol-lowering drugs have shown a significant reduction in the risk of major amputation. ${ }^{21} 22$

To our knowledge, only a few studies have previously investigated the progression of diseases and use of healthcare services before amputation using historical longitudinal data. One case-control study including data collected 7 years before amputation and recommended early referral to a medical specialist to prevent LEA among patients with diabetes, ${ }^{23}$ although a population-based study found that repeated visit to the hospital did not lower the risk of amputation among patients with diabetes and PAD. ${ }^{24}$ Other studies have also shown delayed referral to revascularisation to prevent loss of extremity and inadequate treatment of cholesterol-lowering drug. ${ }^{25} 26$

Nevertheless, the risk of amputation remains high, and some patients remain undiagnosed until it is too late to prevent LEA. ${ }^{27}$ The first step to improving the early identification is to acquire more knowledge of the characteristics of patients, variation and progression of diseases and use of healthcare services prior to amputations. The aim of this study was to explore the progression of LEA-related diseases. We examined the use of medication and the number of contacts with healthcare services during the 14 years leading up to LEA, among all Danish patients that underwent LEAs in 2010 or 2011. Finally, we studied the associations between LEA-related diseases and the 1-year prognosis after the LEA.

\section{METHODS}

\section{Setting}

The Danish healthcare system is tax funded and offers free and equal access to medical care. All citizens have a general practitioner (GP) who provides referrals to specialists and hospital treatments. The GPs are responsible for their patients' medical treatment. Prescribed medications and other healthcare services, such as a physiotherapy, among others, are partly tax funded, with a differential out-of-pocket fee.

\section{Study design and data sources}

We included data from the following five national registries: The National Patient Registry (NPR), which contains information on hospitalisations, including visits to outpatient clinics and emergency rooms, ${ }^{28}$ surgical procedures, coded according to the Nordic Classification of Surgical Procedures, and diagnoses coded according to the International Classification of Diseases (ICD-10); the National Prescription Registry, which contains information on prescribed medications picked up at the pharmacy, ${ }^{29}$ where the data are coded according to the global Anatomical Therapeutic Chemical classification system; the Danish National Health Service Registry for Primary Care, which contains information on all contacts with GPs, including out-of-hours care from GPs and practising medical specialists; ${ }^{430}$ the Danish Civil Registration System, which contains information on gender, date of birth, vital status, spouses and residents; ${ }^{31}$ and the Attainment Registry, which contains data on education level. All Danish citizens are registered with a unique personal identification number (Central Personal Registration CPR number), which allows linkage with all national registries at an individual level. Statistics Denmark provided the data (http://www.danmarksstatistik.dk/en).

\section{Study cohort}

We included patients with at least one of the following surgical procedures, performed between 1 January 2010 and 31 December 2011: hip exarticulation or trans-femoral amputation (ie, AKA), knee disarticulation or transtibial amputation (ie, below-the-knee amputation (BKA) ), foot amputation or toe amputation. See online supplementary material 1 for detailed information. To eliminate trauma-related amputations, we excluded patients with a trauma diagnosis recorded at any time prior to the amputation. We also excluded foreign patients without a CPR number or below 18 years of age. To ensure homogeneity within the groups, we defined an index amputation as the first surgical amputation performed as an AKA, BKA, foot or toe amputation in 2010 and 2011.

\section{Categorisation of amputation procedures}

For patients who received more than one amputation procedure on the same day, the most severe (proximal) procedure was identified for analysis. The severity of different types of amputations (based on surgical codes) was ranked from the most severe procedure as hip exarticulation and transfemoral amputation to the least severe as a toe amputation procedure. A detailed description is present in online supplementary material 1 . When patients had both a left-side and right-side amputation 
code on the same day, the procedure was categorised as a bilateral amputation. AKA and BKA were classified as major amputations, and foot or toe amputations were classified as minor amputations.

\section{Demographics, comorbidities, medications and contacts with healthcare services}

For each patient, we retrieved cumulative registry information on the education level, living conditions, socioeconomic status, place of residence, diagnoses, prescribed medications, contacts with healthcare services, reamputations and death, which had been recorded between 1 January 1997 and 31 December 2012. The Elixhauser Comorbidity Index was used to identify the progression of comorbidities over the 14 years prior to amputation. The Index includes 31 predefined comorbidities; however, in this study, we combined the predefined codes for uncomplicated and complicated diabetes and hypertension. ${ }^{32}$ The Elixhauser Comorbidity Index was supplemented with ICD-10 codes for atherosclerosis, including atherosclerosis in the lower extremities, diabetic neuropathy, retinopathy, nephropathy foot ulcer, other ulcers (not related to diabetes), stroke, emboli, bone cancer and arthrosis; see online supplementary material 1 . The severity of the comorbidity identified at the time of the index amputation was evaluated with the Charlson Comorbidity Index. ${ }^{33}$ We divided the patients into three groups, according to the Charlson Comorbidity Index: 0-1, 2 and $3+$, where a higher score predicted an increased risk of mortality. The prescribed medications were defined as medications that were picked up from the pharmacy at least once each year. The prescribed medications were grouped according to Anatomical Therapeutic Chemical (ACT) codes. The coding and the classifications of drugs were defined by the authors and validated by consensus agreement among three pharmacists who did not participate in the study; see online supplementary material 1.

The NPR registry contains only information on diagnoses recorded during hospitalisation, and not by GPs. Therefore, central diseases were defined by combining the prevalence of the medication (ACT codes) collected from the pharmacy with the registered diagnosis (ICD-10 codes) from hospitals: diabetes ${ }^{\text {comb }}$, atherosclerosis ${ }^{\text {comb }}$, cardiovascular diseases ${ }^{\text {comb }}$ and hypertension ${ }^{\text {comb }}$ (see online supplementary material 1). A visit to a GP was defined as a show-up at the GP clinic, and visits to outpatient clinics included only clinics at the hospitals, while a visit to a medical specialist only includes private clinics.

\section{Ethical approval}

This register-based study included only anonymous data from national registries and had no patient contact. The scientific board of Statistics Denmark and 'Statens Serum Institut' approved the study (project no 704122).

\section{Statistics}

Descriptive data, comorbidities and the use of medication for each of the amputation groups were expressed as frequencies with percentages, for categorical data, or as median and intraquartile range $(\mathrm{IQR}=25$ th to 75th percentile) for continuous data. A comparison between major and minor amputations was made with a $\chi^{2}$ test, for categorical data, and a Kruskal-Wallis test for continuous data. Diagnoses and relevant medications were compared between amputation types and atherosclerosis, diabetes, hypertension and between CVD, diabetes and patients without. The prevalence of diagnoses and use of medications over time are depicted as graphs of the proportions of patients with a given disease and the proportion that used a given medication, respectively. The difference in prevalence over time is expressed as per cent point (pp). The outcome following the amputations, are presented as cumulative incidence plots where death was modelled as a competing event. The data analysis was performed with SAS 9.4, and the cumulative incidence plots were constructed with $\mathrm{R}$ 3.2.2. Graphs of the progression over time were created with GraphPad Prism 6.07, and the flowchart was created in PowerPoint 2010. p Values less than $5 \%$ were considered significant.

\section{RESULTS}

A total of 3375 patients underwent an LEA in Denmark during 2010 and 2011. Of these, $4 \%$ required LEAs due to trauma and were excluded from the cohort (figure 1). Additionally, 352 patients (11\%) were excluded, due to a previous amputation on the same or opposite leg, at the same or a higher level, leaving 2883 patients who fulfilled the criteria for undergoing an index amputation during 2010 and 2011. Major amputations were performed in 1782 patients $(62 \%)$, and minor amputations were performed in 1101 patients (38\%). Patient characteristics are presented in table 1. Among patients with major amputations, $1562(88 \%)$ had not received previous amputations. Among the 266 patients with previous amputations (on a lower level), 101 patients $(38 \%)$ were bilaterally amputated.

\section{Comorbidities and medical treatment in the year of amputation}

Patient diagnoses and current medications that were recorded at the time of the index amputation are presented in tables 2 and 3. Both diabetes and atherosclerosis were diagnosed in $32 \%$ of patients $(577 / 1782)$ with major amputations and $35 \%$ of patients $(382 / 1101)$ with minor amputations. A subgroup analysis of characteristics, comorbidities and medical treatment among patients diagnosed with either CVD including arteriosclerosis, diabetes or neither is presented in table 4 . A total of 2350 (82\%) patients were diagnosed with CVD of which 1185 had CVD without diabetes and 1451 patients were diagnosed with diabetes of which 286 were not diagnosed with CVD. Furthermore, among patients diagnosed with atherosclerosis, 42\% (851/2017) had not received cholesterol-lowering drugs at the time of 


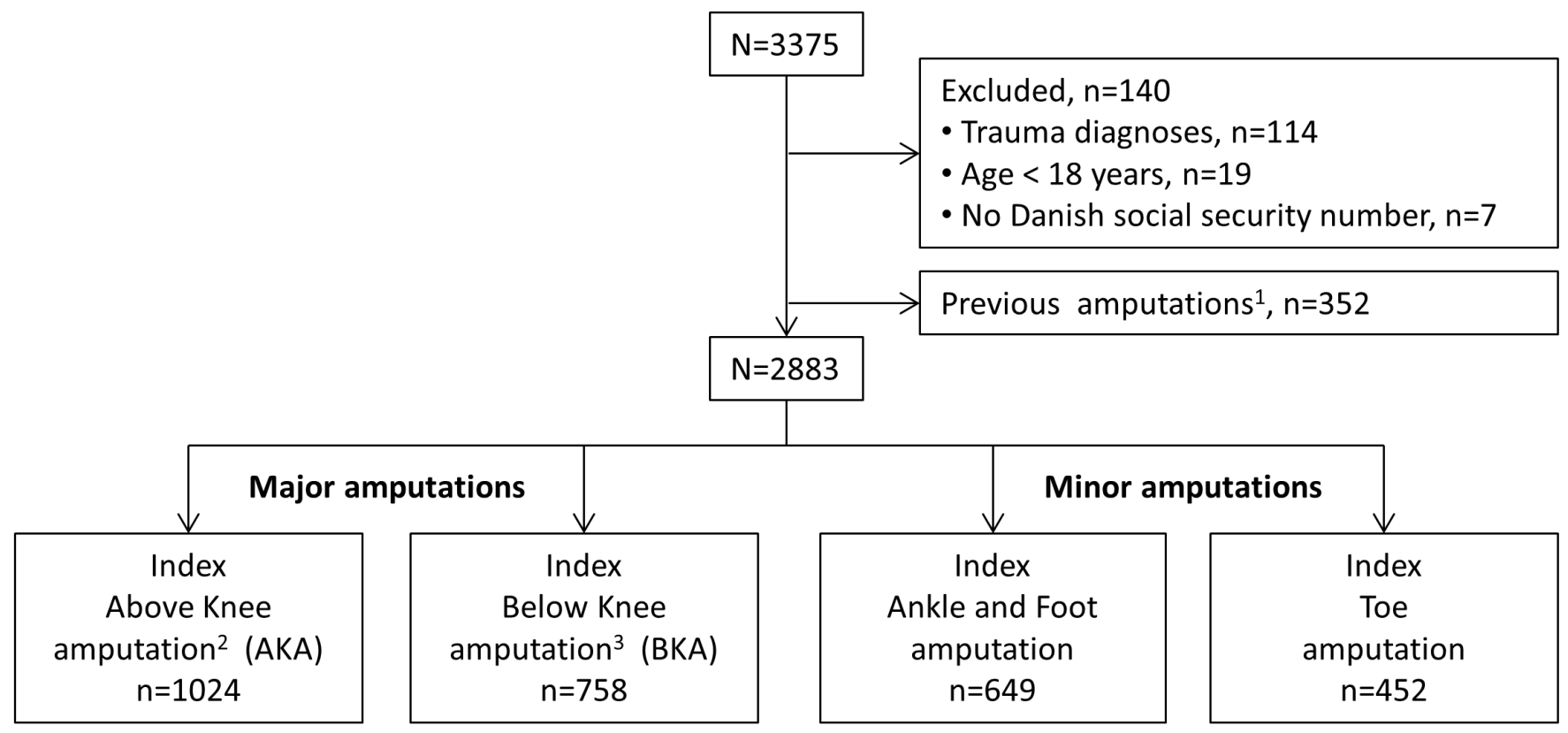

Figure 1 Flowchart shows study selection of patients with lower extremity amputations between 1 January 2010 and 31 December 2011 in Denmark. Legends: ${ }^{1}$ excluded due to previous amputation define as amputation on the same level or bilateral amputation on a higher level than the index amputation in 2010-2011; ${ }^{2}$ include hip exarticulation; ${ }^{3}$ include knee disarticulation.

amputation. The absence of cholesterol-lowering treatment was observed significantly more among patients with major amputations than among those with minor amputations $(46 \% \quad(650 / 1428)$ vs $34 \%$ (201/589); $\mathrm{p}<000.1)$. Among patients diagnosed with CVDs and patients diagnosed with diabetes, $46 \%(543 / 1185)$ and $65 \%(940 / 1451)$ received cholesterol-lowering before the amputation; see table 4. Among patients diagnosed with diabetes, 225 patients (16\%) did not at any time receive insulin or blood glucose-lowering drugs preceding the amputation. The absence of antidiabetic treatment prior to the amputation was observed significantly more often among patients with major amputations than among patients with minor amputations (19\% (134/697) vs 13\% (91/710), p<0.001).

\section{Disease progression and medications during the 14 years prior to amputation}

Figure 2 shows the gradual increases in the proportion of patients with the most common diagnoses (atherosclerosis, diabetes and hypertension) recorded during hospitalisations and the medications used (including antithrombotic agents, cholesterol-lowering treatments, antidiabetic drugs and antihypertensive therapies) during the 14 years prior to the amputation. Among patients undergoing major amputations, the prevalence of atherosclerosis increased from $2 \%$ to $20 \%$ over the first 13 years, and a 58 pp increase was observed during the last year preceding the amputation. During the 14 years, the use of cholesterol-lowering drugs increased from $3 \%$ to $50 \%$. There was a 28 pp difference between patients diagnosed with atherosclerosis who received cholesterol-lowering treatment and not prior to the amputation. Furthermore, the use of antithrombotic drugs increased from $15 \%$ to $65 \%$ during the first 13 years, and the use further increased by 6 per cent point in the last year (figure 2a). Among patients with minor amputations, the prevalence of diabetes increased from $8 \%$ to $40 \%$, and antidiabetic treatments increased from $29 \%$ to $55 \%$. During the last year, the prevalence of diabetes increased by 21 per cent point, and the gap between treatment and diagnosis was only 3 per cent point prior to minor amputation (figure $2 b$ ). Antihypertensive treatments increased from $23 \%$ to $60 \%$ during the first 13 years and then dropped slightly, by 4 per cent point, in the last year prior to a major amputation. Similarly, antihypertensive treatments increased from $20 \%$ to $64 \%$ over the 14 years prior to minor amputations (figure 2c).

The estimated disease progressions, calculated as the combination of the diagnosis prevalence and the medication prevalence, are presented in figure 3 . The progression of diseases prior to a major amputation increased as follows: atherosclerosis ${ }^{\mathrm{comb}}$ increased from $5 \%$ to $53 \%$ during the 14 years, with a 16 per cent point increase in the last 5 years preceding amputation; hypertension ${ }^{\text {comb }}$ increased from $23 \%$ to $63 \%$; cardiovascular diseases ${ }^{\text {comb }}$ increased from $22 \%$ to $70 \%$; and diabetes ${ }^{\text {comb }}$ increased from $17 \%$ to $35 \%$. The use of opioids increased from $10 \%$ to $45 \%$, with an 18 per cent point increase the last 5 years prior to amputation. Further, $32 \%$ received prescribed opioids 3years prior to major amputation (figure 3a). Among patients with minor amputations, the prevalence 
Table 1 Characteristics of patients with lower extremity amputations in 2010-2011 in Denmark

\begin{tabular}{|c|c|c|c|c|}
\hline & & & pputation & Minor amputation \\
\hline & $\begin{array}{l}\text { Total } \\
\text { n (\%) }\end{array}$ & $\begin{array}{l}\text { Above knee } \\
\text { n (\%) }\end{array}$ & $\begin{array}{l}\text { Below knee } \\
\text { n (\%) }\end{array}$ & n (\%) \\
\hline Gender & & & & \\
\hline Male & $1811(63)$ & $544(53)$ & $489(65)$ & $778(71)$ \\
\hline Women, median (IQR) & $78(68 ; 86)$ & $81(72 ; 87)$ & $78(68 ; 85)$ & $72(63 ; 82)$ \\
\hline Social status ${ }^{*}$ & & & & \\
\hline Married $\dagger$ & $1165(40)$ & $378(37)$ & $307(41)$ & $480(44)$ \\
\hline Divorced & $937(32)$ & $293(29)$ & 247 (33) & $397(36)$ \\
\hline Retired & $2055(71)$ & $845(83)$ & $534(71)$ & $676(61)$ \\
\hline Social welfare & $571(20)$ & $155(15)$ & $162(21)$ & $254(23)$ \\
\hline Living arrangement & & & & \\
\hline Living alone & $1514(53)$ & $595(58)$ & $402(53)$ & $517(47)$ \\
\hline Living in rural areas & $1705(59)$ & $634(62)$ & $431(57)$ & $640(58)$ \\
\hline Education & & & & \\
\hline$<9$ year of school & $2549(88)$ & $896(88)$ & $662(87)$ & $991(90)$ \\
\hline Charlson Index & & & & \\
\hline Peripheral vascular procedure & & & & \\
\hline Angioplasty & $89(3)$ & $7(1)$ & $4(1)$ & $78(7)$ \\
\hline Bypass graft & $97(3)$ & $5(0 ; 5)$ & $4(1)$ & $88(8)$ \\
\hline Surgery history & & & & \\
\hline Previous amputation & $266(9)$ & $113(11)$ & $107(14)$ & $46(4)$ \\
\hline$<3$ amputations & $203(7)$ & $84(8)$ & $76(14)$ & $43(4)$ \\
\hline$\geq 3$ amputations & $63(2)$ & $29(3)$ & $31(4)$ & $3(-)$ \\
\hline
\end{tabular}

Values represent the number of patients (\%), unless indicated otherwise.

${ }^{*}$ Missing $\mathrm{n}=12$.

†Married or residing with a partner.

†All ICD-10 diagnoses.

$\S A C T$ codes for main groups.

of atherosclerosis ${ }^{\text {comb }}$ increased from $3 \%$ to $51 \%$ during the 14 years, cardiovascular diseases ${ }^{\text {comb }}$ increased from $16 \%$ to $63 \%$, hypertension ${ }^{\mathrm{comb}}$ increased from $20 \%$ to $66 \%$ and diabetes increased from $29 \%$ to $57 \%$. The use of opioids increased from $9 \%$ to $34 \%$, with a 12 per cent point increase in the last 5 years (figure $3 \mathrm{~b}$ ). In total, $29 \%$ received opioids 3 years before the amputation.
Contacts made to hospitals and GPs during the $\mathbf{1 4}$ years prior to amputation

Patients' visits to the healthcare system (hospitals, outpatient clinics and GPs) during the 14 years prior to amputation are presented in figure 3 . A total of $98 \%$ of the patients contacted healthcare services at least once during the last year prior to amputation. The proportion of patients 
Table 2 Prevalence of comorbidity among patients with lower extremity amputations in 2010-2011 in Denmark

\begin{tabular}{|c|c|c|c|c|c|}
\hline & \multicolumn{3}{|c|}{ Major amputations } & \multicolumn{2}{|c|}{ Minor amputations } \\
\hline & Total, n (\%) & Above knee, n (\%) & Below knee, n (\%) & Total, n (\%) & \\
\hline & $n=1782$ & $n=1024$ & $\mathrm{n}=758$ & $n=1101$ & p Value* \\
\hline Peripheral vascular disorders & $1481(83)$ & $873(85)$ & $608(80)$ & $625(57)$ & $<0.0001$ \\
\hline Atherosclerosis $\dagger$ & $1428(80)$ & $844(82)$ & $584(77)$ & $589(54)$ & $<0.0001$ \\
\hline Hypertension $\ddagger$ & $902(51)$ & $577(56)$ & $441(58)$ & $599(54)$ & 0.18 \\
\hline Diabetes $\ddagger$ & $697(39)$ & $331(32)$ & $366(48)$ & $710(64)$ & $<0.0001$ \\
\hline Diabetic foot ulcer§ & $505(18)$ & $224(22)$ & $281(37)$ & $522(47)$ & $<0.0001$ \\
\hline Neuropathy§ & $174(6)$ & $69(7)$ & $105(14)$ & $230(21)$ & $<0.0001$ \\
\hline Retinopathy§ & $112(6)$ & $37(4)$ & $75(10)$ & $141(13)$ & $<0.0001$ \\
\hline Nephropathy§ & $85(5)$ & $22(2)$ & $63(8)$ & $82(7)$ & 0.0028 \\
\hline Cardiac ischaemia§ & $597(34)$ & $348(34)$ & $249(33)$ & $329(30)$ & 0.04 \\
\hline Cardiac arrhythmia & $536(30)$ & $319(31)$ & $215(28)$ & $232(21)$ & $<0.0001$ \\
\hline Cerebrovascular disease & $540(30)$ & $317(31)$ & $223(29)$ & 195 (18) & $<0.0001$ \\
\hline Congestive heart failure & $401(23)$ & $228(22)$ & $173(23)$ & $191(17)$ & 0.0009 \\
\hline Stroke§ & 401 (23) & $234(23)$ & $167(22)$ & $144(13)$ & $<0.0001$ \\
\hline Arthrosis§ & $320(18)$ & $202(20)$ & $118(16)$ & $195(18)$ & 0.86 \\
\hline Chronic pulmonary diseases & $356(20)$ & $227(22)$ & $129(17)$ & $129(12)$ & $<0.0001$ \\
\hline Fluid and electrolyte disorders & $330(19)$ & $211(21)$ & $119(16)$ & $123(11)$ & $<0.0001$ \\
\hline Emboli§ & $359(20)$ & $231(23)$ & $128(17)$ & $88(8)$ & $<0.0001$ \\
\hline Renal failure & $252(14)$ & $129(13)$ & $123(16)$ & $133(12)$ & 0.11 \\
\hline Tumour without metastasis & $243(14)$ & $143(14)$ & $100(13)$ & $107(10)$ & 0.0018 \\
\hline Alcohol addiction & $227(13)$ & $121(12)$ & $106(14)$ & $122(11)$ & 0.18 \\
\hline Obesity & $130(7)$ & $60(6)$ & $70(9)$ & $127(12)$ & 0.0001 \\
\hline Rheumatoid arthritis & 139 (8) & $77(8)$ & $62(8)$ & $90(8)$ & 0.71 \\
\hline Depression & $124(7)$ & 77 (8) & $47(6)$ & $58(5)$ & 0.069 \\
\hline Dementiađ & $110(6)$ & $69(7)$ & $43(6)$ & $37(3)$ & 0.0006 \\
\hline Liver disease & $79(4)$ & $40(4)$ & $39(5)$ & $51(5)$ & 0.80 \\
\hline Metastatic cancer & $50(3)$ & $36(3)$ & $14(2)$ & $9(1)$ & 0.0002 \\
\hline Weight loss & $43(2)$ & $30(3)$ & $13(2)$ & $12(1)$ & 0.0155 \\
\hline Bone cancer§ & $24(1)$ & $14(1)$ & $10(1)$ & $2(-)$ & 0.0013 \\
\hline
\end{tabular}

${ }^{*} \mathrm{p}<0.05$, major vs minor amputation. Comorbidity, defined according to Elixhauser Comorbidity index.

†Includes only ICD-10- I170;

łIncludes uncomplicated and complicated conditions.

$\S$ Not included in the Elixhauser Comorbidity Index.

IIncluded from the Charlson Comorbidity Index.

contacting their GPs increased from $85 \%$ to $97 \%$, and the mean number of visits to GPs per year increased from 4.5 to 7.7 visits. The proportion of patients attending outpatient clinics increased from $25 \%$ to $76 \%$, and the mean visits to outpatient clinics per year increased from 0.4 to 3.2 visits. During the last year prior to amputation, $2 \%$ of the patients had no contact with GPs or hospitals, $1 \%$ had only contacted hospitals and $18 \%$ had only contacted GPs.

Among 851 patients diagnosed with arteriosclerosis without receiving cholesterol-lowering drugs at any time prior to the amputation, $87 \%$ had visited their GP, 29\% had called out-of-hours care, $47 \%$ had been hospitalised,
$70 \%$ had visited outpatient clinics and $29 \%$ had visited the emergency room during the last year prior to amputation.

\section{Cumulative incidences of death and reamputation}

Figure 4 shows the cumulative incidences of death and reamputation for first year after LEA. The HRs for death the first year after an AKA (compared with toe amputation) were 4.41 (95\% CI 3.44 to 5.66, $\mathrm{p}<0.001)$ with no adjustments, 3.39 (95\% CI 2.64 to $4.37, \mathrm{p}<0.001$ ) after adjusting for demographics (gender, age, social status and living arrangement) and 4.0 (95\% CI 3.09 to 5.19, $\mathrm{p}<0.001$ ) after also adjusting for comorbidities (diabetes, arteriosclerosis, hypertension and use of opioids). The 
Table 3 Prevalence of prescribed medications used by patients with lower extremity amputations in 2010-2011 in Denmark

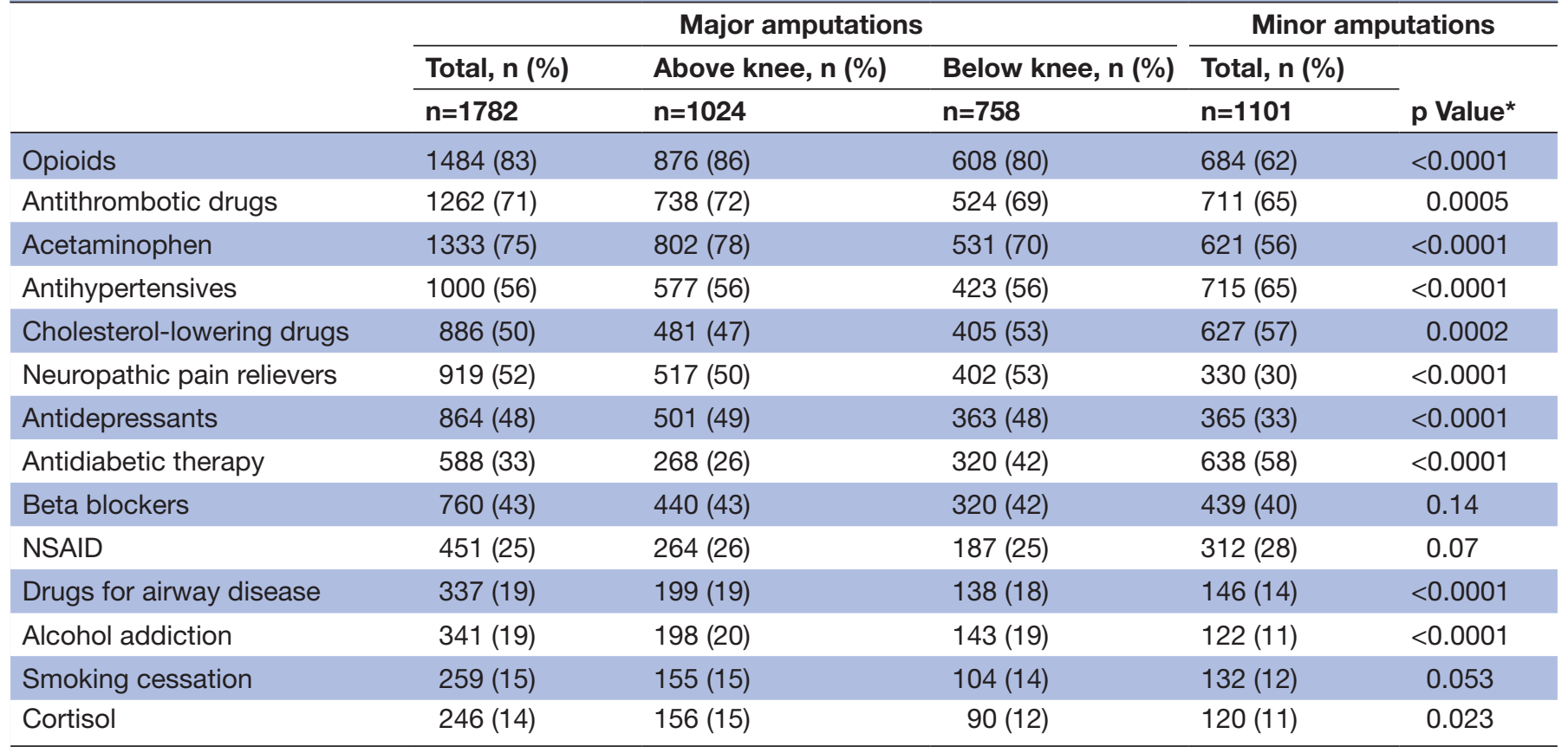

${ }^{*} \mathrm{p}<0.05$, major vs minor amputation.

NSAID, non-steroidal anti-inflammatory drug.

HRs for death the first year after a BKA (compared with foot amputation) were 2.57 (95\% CI 1.97 to 3.19 , $\mathrm{p}<0.001$ ) without adjustments, 2.28 (95\% CI 1.75 to $2.97, \mathrm{p}<0.001$ ) after adjusting for demographics and 2.39 (95\% CI 1.83 to $3.13, \mathrm{p}<0.001$ ) after also adjusting for comorbidity.

The HRs for reamputation the first year after an AKA were 4.16 (95\% CI 3.24 to $5.34, \mathrm{p}<0.001)$ without adjustments, 3.20 (95\% CI 2.49 to 4.13 , $\mathrm{p}<0.001$ ) after adjusting for demographics and 3.69 (95\% CI 2.85 to 4.79 , p<0.001) after adjusting for comorbidity. The HRs for reamputation the first year after a BKA were 2.64 (95\% CI 2.02 to $3.43, \mathrm{p}<0.001$ ) without adjustments, 2.34 (95\% CI 1.79 to $3.05, \mathrm{p}<0.001)$ after adjusting for demographics and $2.4(95 \%$ CI 1.83 to $3.14, \mathrm{p}<0.001)$ after adjusting for comorbidity.

\section{DISCUSSION}

This study showed that the prevalence of atherosclerosis was $70 \%$ and the prevalence of diabetes was $49 \%$ in an unselected national cohort of patients undergoing LEAs. Among patients with atherosclerosis, $42 \%$ had not received cholesterol-lowering treatments, although $87 \%$ of these patients had visited their GP within the last year preceding the amputation. Additionally, $16 \%$ of the patients with diabetes were diagnosed with diabetes the year of the amputation. The majority of patients $(85 \%-$ $97 \%$ ) had contact to their GP within the 14 years prior to amputation, and $64 \%$ were in contact with a hospital outpatient clinic within the 3 years prior to amputation. Moreover, $88 \%$ of patients undergoing major extremity amputation had no previous amputation on a lower level.
Additionally, only $6 \%$ of patients in this cohort had undergone revascularisation prior to amputation. Nevertheless, one out of three patients received prescribed opioids 3 years prior to amputation. Traditionally, LEA has been associated with long-term complications of diabetes. However, the prevalence of CVDs is increasing in Western countries; consequently, the traditional perceptions must be redefined to identify risk factors for LEA. In our national cohort of patients with major amputations, the majority (83\%) were diagnosed with atherosclerosis, and less $(33 \%)$ had diabetes. In comparison, patients with minor amputations had a higher prevalence of diabetes $(64 \%)$ and lower prevalence of atherosclerosis (53\%). Similar distributions were identified by The Global Lower Extremity Amputation Study Group (2000). ${ }^{16}$

According to the guidelines, our results indicate a suboptimal treatment of atherosclerosis and identification of diabetes. There was a 28 per cent point difference between the proportion of patients who received cholesterol-lowering drugs and the proportion of patients diagnosed with atherosclerosis. Also, among patients with diabetes, there was a 6 per cent point gap between patients having diabetes and patients receiving antidiabetic treatment, indicating an unsolved clinical problem in identifying atherosclerosis and diabetes. Indeed, timely treatment might have saved these patients from an extremity amputation. The lack of recognition of symptoms related to PAD among both patients and healthcare professionals may be linked to a lack of knowledge inhibiting patients to react on symptoms and consult their GP in time. ${ }^{34}$ Additionally, only $6 \%$ of the 
Table 4 Characteristics and comorbidities among patients with lower extremity amputation diagnosed with cardiovascular diseases, diabetes or without in 2010-2011

\begin{tabular}{|c|c|c|c|c|c|}
\hline & \multicolumn{3}{|c|}{ In risk of lower limb amputation } & \multirow{3}{*}{$\begin{array}{l}\text { No CVD or diabetes } \\
n=247(\%)\end{array}$} & \multirow[b]{3}{*}{ p Value* } \\
\hline & \multirow[b]{2}{*}{$\mathrm{n}=2636$} & \multirow{2}{*}{$\begin{array}{l}\text { Cardiovascular disease } \\
\mathrm{n}=1185(\%)\end{array}$} & \multirow{2}{*}{$\begin{array}{l}\text { Diabetes } \\
n=1451(\%) \\
\end{array}$} & & \\
\hline & & & & & \\
\hline \multicolumn{6}{|l|}{ Characteristics } \\
\hline Male & $1680(64)$ & $637(54)$ & $1043(72)$ & $131(53)$ & $<0.0001$ \\
\hline Married & $1058(40)$ & $430(36)$ & $628(43)$ & $107(43)$ & 0.0003 \\
\hline working & $197(7)$ & $46(4)$ & $151(10)$ & $60(24)$ & $<0.0001 \dagger$ \\
\hline Retired & $1943(74)$ & $985(83)$ & $958(66)$ & $112(45)$ & \\
\hline Social welfare & 496 (19) & $154(13)$ & $342(24)$ & $75(30)$ & \\
\hline Living in rural areas & $1548(59)$ & $704(59)$ & $844(58)$ & $157(64)$ & 0.5 \\
\hline \multicolumn{6}{|l|}{ Charlson Index } \\
\hline $0-1$ & $376(14)$ & $322(27)$ & $54(4)$ & $170(69)$ & $<0.0001 \ddagger$ \\
\hline 2 & $411(16)$ & $314(27)$ & $97(7)$ & $45(18)$ & \\
\hline 3 & $1849(70)$ & $549(46)$ & $1300(90)$ & $32(13)$ & \\
\hline Previous amputation & $252(10)$ & $55(5)$ & $197(14)$ & $14(6)$ & $<0.0001$ \\
\hline \multicolumn{6}{|l|}{ Multi-morbidities } \\
\hline Comorbidities, median (IQR) & $8(6 ; 10)$ & $6(5 ; 8)$ & $10(7 ; 12)$ & $1(0 ; 2)$ & $<0.0001$ \\
\hline Drugs, median (IQR) & $7(5 ; 9)$ & $6(4 ; 8)$ & $8(6 ; 10)$ & $3(2 ; 5)$ & $<0.0001$ \\
\hline Ulcer & $1360(52)$ & $489(41)$ & $871(60)$ & $80(32)$ & $<0.0001$ \\
\hline Hypertension & $1397(53)$ & $519(44)$ & $878(61)$ & $34(14)$ & $<0.0001$ \\
\hline Arthrosis & $454(17)$ & 227 (19) & $227(16)$ & $61(25)$ & 0.02 \\
\hline Chronic pulmonary diseases & 466 (18) & $250(21)$ & $216(15)$ & $19(8)$ & $<0.0001$ \\
\hline Tumour without metastasis & $310(12)$ & $178(15)$ & $132(9)$ & $40(16)$ & $<0.0001$ \\
\hline Alcohol addiction & $319(12)$ & $156(13)$ & $163(11)$ & $30(12)$ & 0.1 \\
\hline Obesity & $252(10)$ & $28(2)$ & $224(15)$ & $5(2)$ & $<0.0001$ \\
\hline Rheumatoid arthritis & $203(8)$ & $110(9)$ & $93(6)$ & $26(11)$ & 0.006 \\
\hline Liver disease & $109(4)$ & $41(3)$ & $68(5)$ & $21(9)$ & 0.1 \\
\hline Metastatic cancer & $52(2)$ & $40(3)$ & $12(1)$ & 7 (3) & $<0.0001$ \\
\hline \multicolumn{6}{|l|}{ Prescribed medication } \\
\hline Opioids & $2027(77)$ & $93(84)$ & $1034(71)$ & $141(57)$ & $<0.0001$ \\
\hline Cholesterol-lowering drugs & $1483(56)$ & $543(46)$ & $940(65)$ & $30(12)$ & $<0.0001$ \\
\hline Antithrombotic drugs & $1919(73)$ & $855(72)$ & $1064(73)$ & $54(22)$ & 0.5 \\
\hline Antihypertensive & 1647 (62) & $611(52)$ & $1036(71)$ & $68(28)$ & $<0.0001$ \\
\hline Neuropathic pain relievers & $1162(44)$ & $580(49)$ & $582(40)$ & $87(35)$ & $<0.0001$ \\
\hline Beta blockers & $1161(44)$ & $475(40)$ & $686(47)$ & $38(15)$ & 0.0002 \\
\hline Alcohol addiction & $420(16)$ & $226(19)$ & $194(13)$ & $43(17)$ & $<0.0001$ \\
\hline Drugs for airway disease & $459(17)$ & $240(20)$ & $219(15)$ & $24(10)$ & 0.0005 \\
\hline
\end{tabular}

${ }^{*} \mathrm{p}<0.05$, cardiovascular disease vs diabetes.

$t p$ Value represents the distribution of working, retired and social welfare between patients with CVD, diabetes or without.

$\ddagger \mathrm{p}$ Value represents the distribution of Charlson Index between patients with CVD, diabetes or without.

Cardiovascular disease includes atherosclerosis, peripheral vascular disorders, cardiac ischaemia, emboli, stroke, cerebrovascular disease.

Diabetes includes antidiabetic therapy.

patients had received revascularisations (angioplasty or bypass) prior to the index amputation. These results were concerning as revascularisation surgery still is an essential part of the treatment for critical ischaemia in lower extremities. ${ }^{35} 36$ Similarly, Moxey et al also found a low prevalence of revascularisation of $9 \%$ in an unselected, nationwide cohort. ${ }^{37}$ However, Ahmad et al found a 30\% prevalence of revascularisation in an unselected population cohort in England. ${ }^{11}$ Ahmad et al also demonstrated demographic variations in the prevalence of amputations 

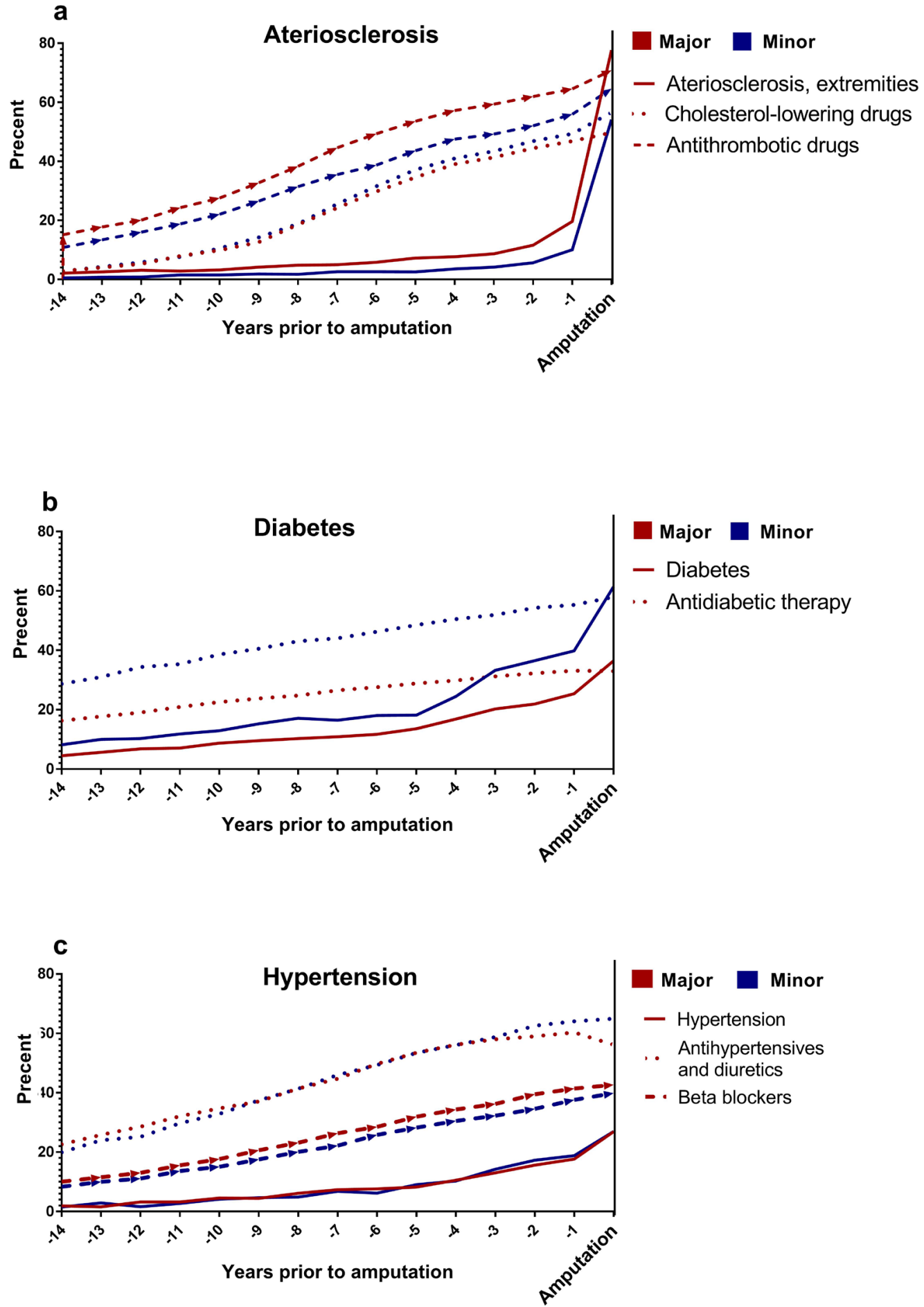

Figure 2 Prevalence of comorbidities and prescribed medications during the 14 years preceding major and minor lower extremity amputations.

and revascularisations, which were associated with social inequalities and the presence of chronic diseases.

The results of this study point towards several possibilities for preventing LEA. The finding that $29 \%$ of the patients received intensive pain treatment already 3 years prior to major amputation indicates symptoms of critical extremity ischaemia. For comparison, 2.6\% of the Danish population collected prescribed opioids in
$2011 .^{38}$ Thus, it is essential that distal lower extremity pain should be recognised as a symptom of PAD to ensure that patients are referred to specialists to confirm the diagnosis. ${ }^{39}{ }^{40}$ In Denmark, ankle and toe blood pressures are measured to calculate the Ankle-Brachial Index (ABI) ${ }^{41}$ a non-invasive diagnostic test for PAD. ${ }^{42}$ This procedure is mainly performed at the hospitals and rarely by the GP. Throughout the 14 years preceding amputation, 
A
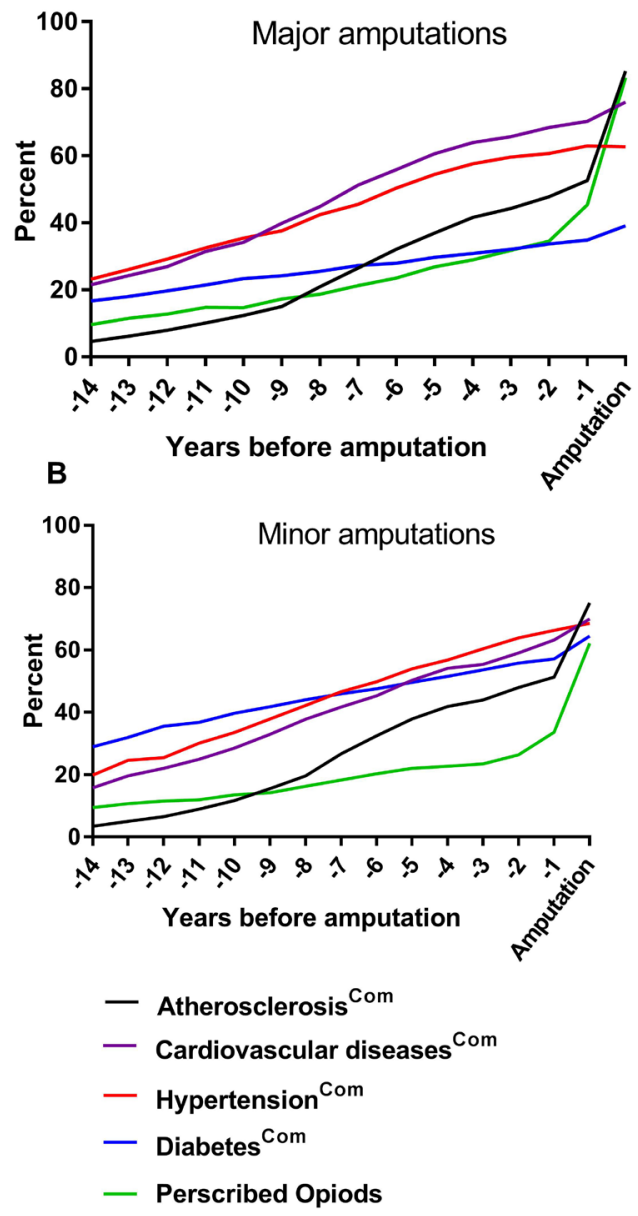

C
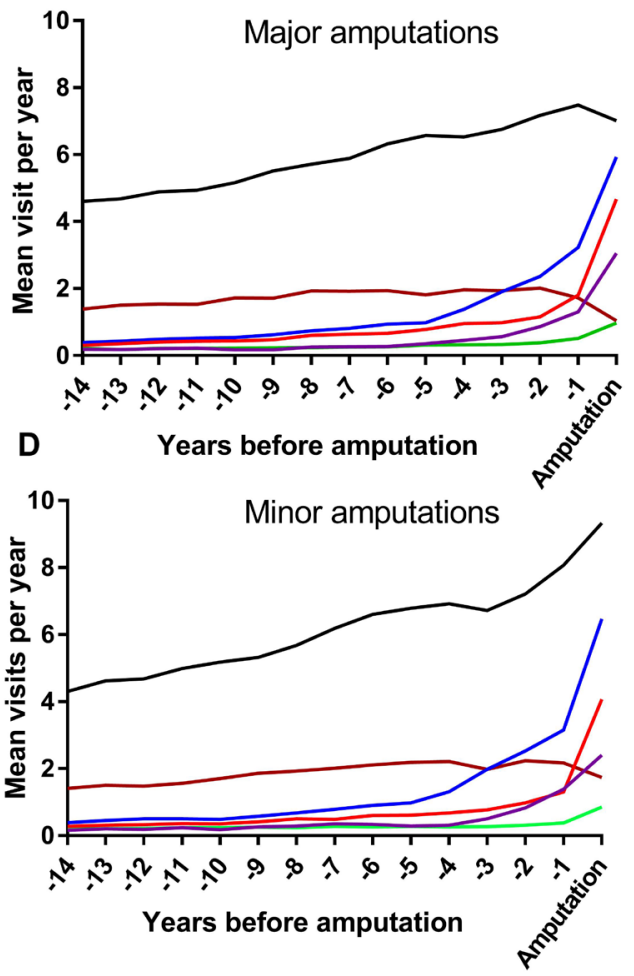

- General Practitioner

- Out-of- horus care by GP

- Admission to hospital

- Out-patient clinics at hospitals

- Medical specialist

- Emergency room

Figure 3 Fourteen years of estimated progression of chronic diseases and contacts to healthcare system preceding (a, c) major and (b, d) minor lower extremity amputations. The prevalence of comorbidities, defined by both ICD-10 coding and the use of prescribed medications (ACT code), was estimated each year. GP, general practitioner.

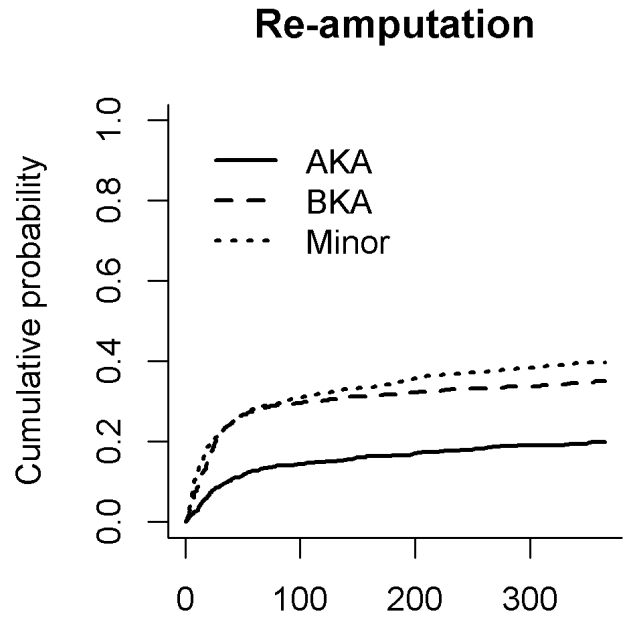

Days since Index amputation

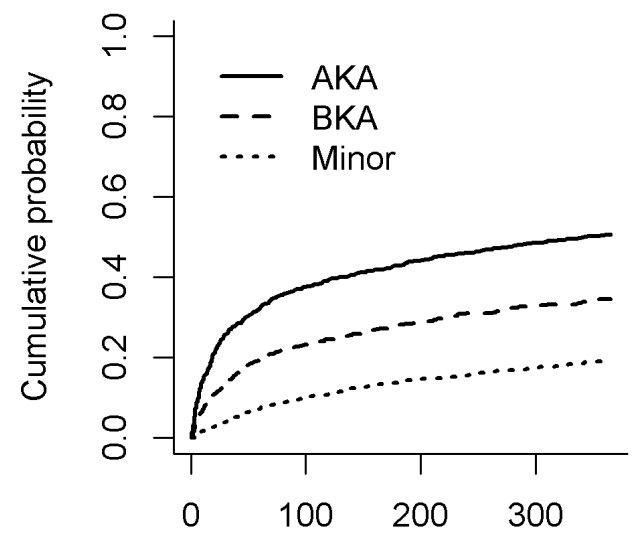

Days since Index amputation

Figure 4 One-year cumulative outcomes. The cumulative probabilities of (left) reamputation procedures and (right) survival are shown for patients who received major (above-the-knee amputation (AKA) and below-the-knee amputation (BKA)) and minor lower extremity amputations. 
the majority of patients in this study had regular and increasing contact with their GPs (prevalence increase from $85 \%$ to $97 \%$ ). Thus, early identification might be feasible because patients do seek medical advice in the years prior to amputation. Furthermore, the proportion of patients in contact with outpatient clinics or were admitted to hospital increased from $25 \%$ and $76 \%$ and from $32 \%$ to $49 \%$ during the 14 years preceding the amputation. Buckley et al followed patients with diabetes for 7 years prior to LEA and concluded a need for early referral to specialists to reduce the risk of LEA ${ }^{23}$ It has been suggested that PAD screening could be performed with non-invasive methods like the $\mathrm{ABI} .{ }^{43}$ Other studies have indicated that routine screening could promote preventive treatment and that a screening strategy could cost-effectively prevent the progression of $\mathrm{PAD}$ and cardiovascular events. ${ }^{44}$ Alternatively, Brand ${ }^{46}$ and Boulton et $a t^{47}$ have suggested that a simple clinical examination of a patient's feet could indicate a need to confirm PAD. Thus, treatment could be initiated (including specialist referrals) to prevent ulcers due to ischaemia and, thus, prevent LEA. This study supports the conclusion made by Jones $e t$ al that calls for education programs to focus on prevention and early identification to ensure adequate treatment for preventing LEA. ${ }^{5}$

In this study, the majority of patients (92\%) had no history of previous amputation preceding the index major amputation. Heyer et al reported that $92 \%$ of their patients had no previous amputation based on data from health insurance companies, ${ }^{12}$ and Buckley et al found that $28 \%$ of a selected cohort of patients with diabetes had a history of amputations. ${ }^{23}$ The present study confirms that the risk of death is highest among patients with major amputation. In contrast, neither demographics nor comorbidities could explain the high risk of death. Thus, other factors must affect the outcome after LEA, such as the general health status and the nutritional status of a patient. Also, factors related to the perioperative treatment, like a delay to surgery, could have a negative impact on the outcome. ${ }^{48}$ Similar results were reported by Jones et al, Hoffstad et al and Wiessman et al, who called for more comprehensive, multi-disciplinary efforts. ${ }^{5} 710$

The strength of this study was the use of a national cohort based on the national registry, which contained information recorded over a period of 14 years before the amputation. Furthermore, we could cross-link data in various registries at an individual level, which made it possible to follow patients over time. The main limitation was the lack of a control group. An age-matched, sex-matched and geographically matched control group could allow differentiation between disease progression due to ageing and disease progression that leads to amputation. An inherent limitation was that the data did not allow for an estimation of patient compliance with the prescribed medication. Further, it was not possible to access neither the diagnosis recorded by the GP, as these data are not included in the national registry, nor the indication for the prescribed medication as this has just recently been included in the registry. Finally, data on examinations such as ABI prior to the amputation would have provided a more comprehensive overview of the limb-saving procedure.

\section{CONCLUSION}

In this study, one-third of patients with LEA were living with undiagnosed or untreated atherosclerosis and one out of six were living with undiagnosed diabetes despite a regular contact with their GPs and outpatient clinics for several years prior to the amputation. For the majority of patients undergoing major LEAs, the amputation was a first-time amputation. Additionally, only a small number of patients underwent limb-saving procedures, although one in three had received opioid prescriptions several years before the amputation. The overall findings of this study suggest that the need for opioids, combined with the presence of hypertension, diabetes or another CVD, could be an indication of $\mathrm{PAD}$, which is highly associated with LEA. Further, clinicians are encouraged to initiate medical treatment supplemented with a careful inspection of the patient's feet as this non-invasive examination may detect an early indication of low circulation.

\section{Author affiliations}

${ }^{1}$ Clinical Research Centre Copenhagen University Hospital, Hvidovre, Denmark ${ }^{2}$ Department of Orthopaedic Surgery, Copenhagen University Hospital, Hvidovre, Denmark

${ }^{3}$ Department of Public Health Section of Biostatistics, University of Copenhagen, Copenhagen, Denmark

${ }^{4}$ Copenhagen Wound Healing Centre, University Hospital of Copenhagen, Copenhagen, Denmark

${ }^{5}$ Traumatic Brain Injury Unit, Rigshospitalet, Clinic of Neurorehabilitation, Copenhagen, Denmark

Acknowledgements We acknowledge the contribution from Research Services, Statistics Denmark, and thank Jørn K. Petersen for his assistance. We especially thank Nasrin Faqir, for her contribution to data management and analysis.

Contributors SJ and JP describe the study. PSJ and OA ensured funding. PSJ, JP, KKM, IP and OA designed the study. PSJ and JP applied for data at Statistics Denmark. PSJ and JP provided the statistical expertise. IP, KKM and OA provided the clinical and medical expertise. PSJ and JP performed the data management and analysis. All authors helped interpret the data. The accuracy of data and analysis was reviewed by all authors who can take responsibility for the integrity of the data and the accuracy of the data analysis. PSJ drafted the manuscript. All authors reviewed and critically revised the manuscript for intellectual content and approved the final version of the manuscript.

Funding This study was funded by the Novo Nordic Foundation grant number NNF120C0002017 and Copenhagen University Hospital, Hvidovre Research Foundation. None of the sponsors were involved in the design of the study, collection, analysis, interpretation of data and in writing the manuscript.

Competing interests None declared.

Patient consent The study only used anonymised data from national registries. Provenance and peer review Not commissioned; externally peer reviewed.

Data sharing statement The datasets supporting the conclusions of this article are available in the Statistics Denmark, http://www.dst.dk/. Statistics Denmark managed and provided the secured access In according to Danish regulations; data are available by applying Statistics Denmark.

Open Access This is an Open Access article distributed in accordance with the Creative Commons Attribution Non Commercial (CC BY-NC 4.0) license, which permits others to distribute, remix, adapt, build upon this work non-commercially, and license their derivative works on different terms, provided the original work is 
properly cited and the use is non-commercial. See: http://creativecommons.org/ licenses/by-nc/4.0/

(C) Article author(s) (or their employer(s) unless otherwise stated in the text of the article) 2017. All rights reserved. No commercial use is permitted unless otherwise expressly granted.

\section{REFERENCES}

1. Suckow BD, Goodney PP, Nolan BW, et al. Domains that determine Quality of Life in vascular amputees. Ann Vasc Surg 2015;29:722-30.

2. Ries Z, Rungprai C, Harpole B, et al. Incidence, risk factors, and causes for thirty-day unplanned readmissions following primary lower-extremity amputation in patients with diabetes. J Bone Joint Surg Am 2015;97:1774-80.

3. Curran T, Zhang JQ, Lo RC, et al. Risk factors and indications for readmission after lower extremity amputation in the American College of Surgeons National Surgical Quality Improvement Program. J Vasc Surg 2014;60:1315-24.

4. Moxey PW, Gogalniceanu P, Hinchliffe RJ, et al. Lower extremity amputations - a review of global variability in incidence. Diabet Med 2011;28:1144-53.

5. Jones WS, Patel MR, Dai D, et al. High mortality risks after major lower extremity amputation in Medicare patients with peripheral artery disease. Am Heart J 2013;165:809-15.

6. Scott SW, Bowrey S, Clarke D, et al. Factors influencing shortand long-term mortality after lower limb amputation. Anaesthesia 2014:69:249-58.

7. Hoffstad O, Mitra N, Walsh J, et al. Diabetes, lower-extremity amputation, and death. Diabetes Care 2015;38:1852-7.

8. Hoffmann M, Kujath P, Flemming A, et al. Survival of diabetes patients with major amputation is comparable to malignant disease. Diab Vasc Dis Res 2015;12:265-71.

9. Rosen N, Gigi R, Haim A, et al. Mortality and reoperations following lower limb amputations. Isr Med Assoc J 2014;16:83-7.

10. Wiessman MP, Liberty IF, Segev RW, et al. Clinical characteristics and survival of patients with diabetes mellitus following non-traumatic lower extremity amputation. Isr Med Assoc J 2015;17:145-9.

11. Ahmad N, Thomas GN, Gill P, et al. Lower limb amputation in England: prevalence, regional variation and relationship with revascularisation, deprivation and risk factors. A retrospective review of hospital data. J R Soc Med 2014;107:483-9.

12. Heyer K, Debus ES, Mayerhoff L, et al. Prevalence and regional distribution of lower limb amputations from 2006 to 2012 in Germany: a population based study. Eur J Vasc Endovasc Surg 2015;50:761-6.

13. Humphries MD, Brunson A, Hedayati N, et al. Amputation risk in patients with diabetes mellitus and peripheral artery disease using statewide data. Ann Vasc Surg 2016;30:123-31.

14. Nelson MT, Greenblatt DY, Soma G, et al. Preoperative factors predict mortality after major lower-extremity amputation. Surgery 2012;152:685-96.

15. Dinesh Shah A, Langenberg C, Rapsomaniki E, et al. Type 2 diabetes and incidence of a wide range of cardiovascular diseases: a cohort study in 1.9 million people. The Lancet 2015;385(Suppl 1):S86.

16. Unwin N, Airey M, Williams R, et al. Epidemiology of lower extremity amputation in centres in Europe, North America and East Asia. The global Lower Extremity Amputation Study Group. BrJSurg 2000;87:328-37.

17. Organisation mondiale de la santé. Global status report on noncommunicable diseases 2014: attaining the nine global noncommunicable diseases targets; a shared responsibility. Geneva: World Health Organization, 2014.

18. Fowkes FG, Rudan D, Rudan I, et al. Comparison of global estimates of prevalence and risk factors for peripheral artery disease in 2000 and 2010: a systematic review and analysis. Lancet 2013;382:1329-40.

19. Criqui $\mathrm{MH}$, Aboyans V. Epidemiology of peripheral artery disease. Circ Res 2015;116:1509-26.

20. Carthy ER. Lower limb peripheral arterial disease (clinical guideline 147): a guideline summary. Ann Med Surg 2013;2:26-30.
21. Hsu CY, Chen YT, Su YW, et al. Statin therapy reduces future risk of lower limb amputation in patient with diabetes and peripheral artery disease. J Clin Endocrinol Metab 2017:2373-81.

22. DeCarlo C, Scher L, Shariff S, et al. Statin use and other factors associated with mortality after major lower extremity amputation. $J$ Vasc Surg 2017;66:216-25.

23. Buckley CM, Ali F, Roberts GA, et al. Timing of access to secondary healthcare services and lower extremity amputations in patients with diabetes: a case-control study. BMJ Open Diabetes Res Care 2015;3:e000069.

24. Humphries MD, Brunson A, Li CS, et al. Amputation trends for patients with lower extremity ulcers due to diabetes and peripheral artery disease using statewide data. J Vasc Surg 2016;64:1747-55.

25. Reinecke $H$, Unrath $M$, Freisinger $E$, et al. Peripheral arterial disease and critical limb ischaemia: still poor outcomes and lack of guideline adherence. Eur Heart J 2015;36:932-8.

26. Sohn MW, Meadows JL, Oh EH, et al. Statin use and lower extremity amputation risk in nonelderly diabetic patients. J Vasc Surg 2013;58:1578-85.

27. Halter JB, Musi N, McFarland Horne F, et al. Diabetes and cardiovascular disease in older adults: current status and future directions. Diabetes 2014;63:2578-89.

28. Lynge E, Sandegaard JL, Rebolj M. The Danish National Patient Register. Scand J Public Health 2011;39(7 Suppl):30-3.

29. Kildemoes HW, Sørensen HT, Hallas J. The Danish National Prescription Registry. Scand J Public Health 2011;39(7 Suppl):38-41.

30. Andersen JS, Olivarius NF, Krasnik A. The Danish National Health Service Register. Scand J Public Health 2011;39(7 Suppl):34-7.

31. Pedersen CB. The Danish Civil Registration System. Scand J Public Health 2011;39(7 Suppl):22-5.

32. Elixhauser A, Steiner C, Harris DR, et al. Comorbidity measures for use with administrative data. Med Care 1998;36:8-27.

33. Charlson ME, Pompei P, Ales KL, et al. A new method of classifying prognostic comorbidity in longitudinal studies: development and validation. J Chronic Dis 1987;40:373-83

34. Swaminathan A, Vemulapalli S, Patel MR, et al. Lower extremity amputation in peripheral artery disease: improving patient outcomes. Vasc Health Risk Manag 2014;10:417-24.

35. Moxey PW, Hofman D, Hinchliffe RJ, et al. Volume-outcome relationships in lower extremity arterial bypass surgery. Ann Surg 2012;256:1102-7.

36. Conte MS, Pomposelli FB, Clair DG, et al. Society for Vascular Surgery practice guidelines for atherosclerotic occlusive disease of the lower extremities: management of asymptomatic disease and claudication. J Vasc Surg 2015;61(3 Suppl):2S-41.

37. Moxey PW, Hofman D, Hinchliffe RJ, et al. Epidemiological study of lower limb amputation in England between 2003 and 2008. Br J Surg 2010;97:1348-53.

38. Danish National Health Board. The consumption of opiods in Denmark, 2016.

39. Papia G, Mayer P, Kelton D, et al. Just leg pain? Think again: what health leaders must know about peripheral arterial disease. Healthc Manage Forum 2015;28(6 Suppl):S5-9.

40. Farber A, Eberhardt RT. The current state of critical limb ischemia: a systematic review. JAMA Surg 2016;151:1070-7.

41. Sillesen H, Falk E. Peripheral artery disease (PAD) screening in the asymptomatic population: why, how, and who? Curr Atheroscler Rep 2011;13:390-5.

42. Beard JD. ABC of arterial and venous disease: chronic lower limb ischaemia. BMJ 2000;320:854-7.

43. Sillesen $\mathrm{H}$, Falk E. Why not screen for subclinical atherosclerosis? The Lancet 2011;378:645-6.

44. Sigvant B, Henriksson M, Lundin F, et al. Asymptomatic peripheral arterial disease: is pharmacological prevention of cardiovascular risk cost-effective? Eur J Cardiovasc Prev Rehabil 2011;18:254-61.

45. Vaidya A, Joore MA, Ten Cate-Hoek AJ, et al. Screen or not to screen for peripheral arterial disease: guidance from a decision model. BMC Public Health 2014;14:89.

46. Brand PW. Tenderizing the foot. Foot Ankle Int 2003;24:457-61.

47. Boulton AJ, Vileikyte L, Ragnarson-Tennvall G, et al. The global burden of diabetic foot disease. Lancet 2005;366:1719-24.

48. Moxey PW, Hofman D, Hinchliffe RJ, et al. Delay influences outcome after lower limb major amputation. Eur J Vasc Endovasc Surg 2012;44:485-90. 